\title{
Pengembangan Framework untuk Mengukur Tingkat Keberhasilan Implementasi Reverse Logistics
}

\author{
Farida Pulansari ${ }^{*}$, Dwi Sukma Donorianto ${ }^{1}$, Iriani $^{1}$
}

\begin{abstract}
Electronic waste (E-waste) is growing attention at the end of this decade. E-waste must be managed properly. E-waste has a negative impact on the environment. E-waste contain B3 (Bahan Berbahaya dan Beracun - Dangerous and Poissonous Material). Reverse Logistics $(\mathrm{RL})$ is one of the approaches that able to solve these problems. The use of secondary materials through the process of remanufacturing, recycling, refurbishing, recondition are the strategies for minimizing the number of e-waste. Many companies claim successfully implementing of RL. However, there are no clear indicators or parameters to assess the success of RL implementation. In this research we propose the design of reverse logistics maturity framework. Grounded Theory (GT) is chosen to design this framework. GT is a research methodology involving the construction of theory based on phenomena. This framework will be divided into five levels of maturity: Level Conventional, Managed, Developed, Innovative and Optimized. As a case study we implemented the proposed framework to three consumer electronics companies in Indonesia, and we found that those companies were in the Level Managed.
\end{abstract}

Keywords: Reverse logistics, framework, maturity, waste, level, indicator.

\section{Pendahuluan}

Beberapa isu-isu lingkungan seperti perubahan lingkungan (Climate Change), menurunnya keanekaragaman hayati (biodiversity), pencemaran lingkungan karena adanya B3 (Bahan Berbahaya dan Beracun), keterbasan jumlah sumber daya alam serta masalah waste yang merupakan efek samping dari kegiatan industri secara global, mengharuskan manusia untuk berpikir kreatif dan inovatif. Dikarenakan masalah keterbatasan sumber daya alam serta meminimasi jumlah waste, maka Mutha dan Pokharel [1] mengusulkan perusahaan harus mengimplementasikan beberapa hal antara lain legislation, social responsibility, corporate imaging, environmental concern, economic benefit dan customer awareness. Konsep tersebut diharapkan perusahaan mampu menciptakan produk yang ramah lingkungan dengan memanfaatkan secondary material sebagai bahan baku.

Beberapa teknik telah dikembangkan untuk mengatasi permasalahan tersebut. Reverse Logistics (RL) merupakan salah satu teknik yang cukup mendapatkan perhatian dan dianggap sesuai dengan permasalahan e-waste. RL telah diimplementasikan sekitar tahun 1980an. Telah banyak perusahaanperusahaan yang menyatakan keberhasilan implementasi RL dan mendapatkan banyak manfaat.

\footnotetext{
${ }^{1}$ Fakultas Teknologi Industri, Jurusan Teknik Industri, Univesitas Pembangunan Nasional "Veteran" Jawa Timur, Jl. Rungkut Madya Surabaya 60294. Indonesia.

Email: pulansari@gmail.com, sukmadewi2004@gmail.com, iriani123456@gmail.com
}

* Penulis korespondensi
Stock [2] menganalisis RL merupakan salah satu cara untuk mengurangi biaya, meningkatkan pendapatan dan membantu untuk memperoleh keuntungan pasar. Di sisi lain, Chouinard et al., [3] menyatakan bahwa dengan integrasi yang baik antara RL dengan sistem informasi yang tepat akan memberikan informasi yang up-date diantara para pelaku supply chain. Survei yang dilakukan oleh Moore [4] terhadap 125 perusahaan manufaktur, dihasilkan bahwa RL memberikan dampak positif terhadap perndapatan perusahaan melalui remanufacturing sekitar 50-70\%. Kepuasan konsumen dan peningkatan performance perusahaan juga naik secara signifikan setelah perusahaan mengimplementasikan RL (Pollock [5]). Kumar dan Putnam [6] lewat penelitiannya mendapatkan hasil bahwa implementasi RL telah memberikan keuntungan sebesar $74 \%$ untuk energy savings, 90\% untuk penggunaan $n a-$ tural resources, $97 \%$ reduksi mining waste, $88 \%$ reduksi air emission dan $76 \%$ untuk water reduction. Lebih banyak manfaat yang didapatkan antara lain asset utilization, asset recovery, profit maximization, to fulfill the environmental obligations serta customer relations management telah dikemukakan oleh Rakesh Verma [7]. Pendapat yang sama juga dikemukakan oleh Wrap [8] bahwa implementasi RL akan memberikan dampak yang siginifikan bagi perusahaan seperti bagaimana pengelolaan manajemen limbah, serta keselamatan serta kesehatan kerja.

Disain framework ini sangat perlu dilakukan, dikarenakan tidak ada parameter yang jelas untuk setiap tingkat kematangan implementasi RL. Karakteristik serta batasan yang jelas diperlukan guna menumbuhkan effort bagi perusahaan untuk me- 
ningkatkan level dan strategi. Rancangan Framework Maturity of $R L$ ini penting dikarenakan beberapa fenomena antara lain:

(1) Banyaknya klaim atas keberhasilan implementasi RL di beberapa perusahaan, meskipun tidak dijelaskan indikator atau parameter yang jelas tentang kesuksesan tersebut. Adapun macam-macam klaim tersebut antara lain: Penelitian dari Rose et al. [9] yang menyatakan bahwa Kodak dan Xerox berhasil mengimplementasikan RL di perusahaannya, dengan hanya mengandalkan keterlibatan third parties services. Wu dan Cheng [10] melaporkan bahwa AT \& T Network System Division telah berhasil menghemat $\$ 100$ million dalam 19 bulan setelah mengimplementasikan RL HP Plant Patners dapat mengurangi sekitar 18 million pound material dari tempat pembuangan akhir dengan berkolaborasi dengan UPS sebagai collection center (Wu dan Cheng [10]).

(2) Banyaknya peneliti yang menyatakan kunci sukses implementasi RL. Namun klaim tersebut hanya didasarkan dari obyek yang diteliti saja belum bersifat umum dan terstandarisasi. Hal ini menyebabkan tiap-tiap peneliti memiliki tolok ukur yang berbeda-beda dalam menentukan kunci keberhasilan implementasi RL. Adapun pernyataan kunci sukses implementasi RL antara lain: Ho et al. [11] menyimpulkan bahwa kunci sukses implementasi RL terdiri dari 4 faktor yaitu: Company background (number of staff, business field, roles in the SC), degree of recognition and perception (recognition of $R L$, perception of $R L$ ) dan internal and external factors. Internal factor yang terdiri dari company finances and resources support dan company human resources support. Faktor external terdiri dari business partners in SC and government support. Lau dan Wang [12] menyatakan bahwa terdapat 2 faktor kunci keberhasilan RL antara lain external factors: public awareness, legislation, support of SC partners dan internal factors: company policies, strategic planning, top management commitment, resistance to change, information and technological systems, financial resources, personnel resources, performance metrics dan quality of return product.

\section{Metode Penelitian}

\section{Konsep Reverse Logistics (RL)}

Reverse Logistics (RL) menurut Rogers dan Tibben [13] adalah "Process of planning, implementing and controlling the efficient, cost-effective flow of raw materials, in-process inventory, finished goods and related information from the point of consumption to the point of origin for the purpose of recapturing value or proper disposal". Konsep di atas menggam- barkan bahwa RL adalah sebuah proses perencanaan, implementasi sekaligus pengontrolan mulai dari unsur raw material, proses kerja sampai menjadi sebuah produk jadi sampai produk tersebut habis masa pakainya dengan informasi sebagai penunjang.

Dalam studinya deBrito et al. [14] menyatakan beberapa kondisi produk yang dapat dikategorikan dalam RL. Adapun sebab-sebab produk mengalami RL dapat disebabkan karena beberapa hal antara lain: manufacturing return, commercial return (B2B and B2C), B2B adalah short-life product dan B2C adalah product quality, product recall, warranty return, service return, end-of-use return, dan end-oflife return. Rogers dan Tibben [13] mengemukaan bahwa aktivitas dalam reverse logistics adalah "processing returned merchandise due to damage, seasonal inventory, restock, salvage, recalls, and excess inventtory. It also includes recycling programs, hazardous material programs, obsolete equipment disposition, and asset recovery". Kriteria di atas menjelaskan bahwa RL memiliki ruang lingkup yang cukup besar untuk kategori produk yang harus dikembalikan ke perusahaan mulai dari kesalahan pada proses manufaktur, produk-produk yang memiliki umur ekonomis yang relatif singkat, produkproduk dengan kesalahan spesifikasi baik bentuk, fungsi ataupun yang lainnya, adanya sistem jaminan apabila produk yang diterima oleh konsumen tidak sesuai dengan spesifikasi yang ditawarkan. Kemudian adanya bagian dari layanan/ service yang diberikan oleh perusahaan kepada konsumen sebagai bagian dari layanan customer satisfaction, adanya produk yang habis masa pakainya dan hidupnya sehingga kesemuanya di atas perlu adanya proses lanjutan untuk mengantisipasi menumpuknya barang akibat tidak sesuai fungsi, jumlah, standar dan spesifikasi lainnya.

\section{Grounded Theory (GT)}

Heath dan Cowley [15], Walker dan Myrick [16], Bernon et al. [17], dan Denk et al. [18] telah mengambil kesimpulan dari Glaser dan Strauss, bahwa GT adalah "Research methodology findings emphasize the qualitative theory of observation data in the field with empirical inductive method (the theory of amount of data), which is the discovery or construction generative theory using the data as evidence". GT adalah sebuah teorisasi data. Teorisasi data adalah sebuah metode penyusunan teori yang berorientasi tindakan/ interaksi/proses yang benarbenar terjadi di lapangan. Penelitian ini bertolak dari bagaimana implementasi yang terjadi di lapangan. Penelitian ini bertolak dari suatu teori yang bertujuan untuk melihat phenomena atau kejadian suatu teori yang bertujuan untuk menguji 
STAGES OF GROUNDED THEORY

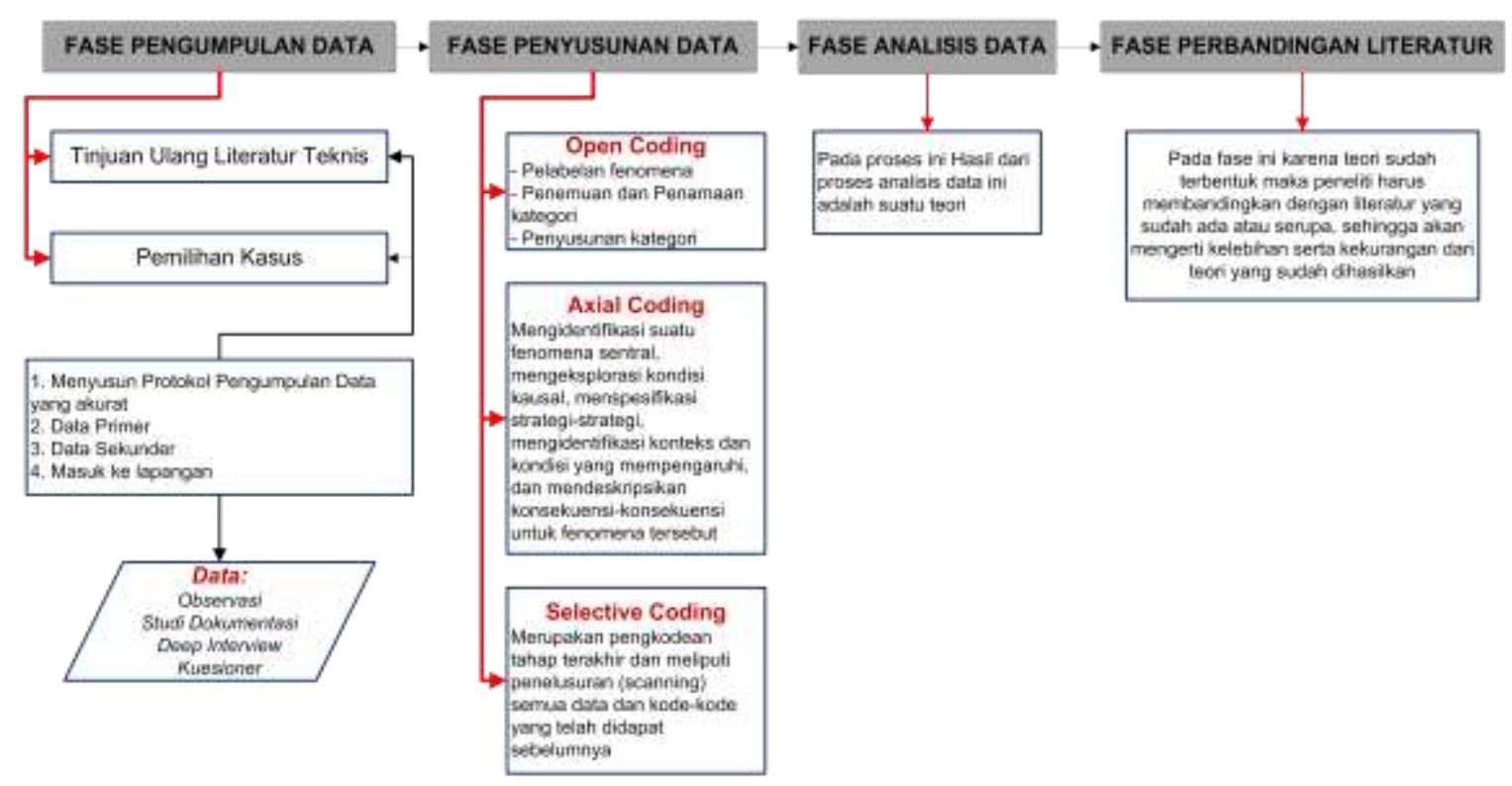

Gambar 1. Langkah-langkah GT

luar biasa yang terjadi di lapangan. Teori yang dihasilkan harus sesuai dengan prosedur dan terencana serta sistematis. Metode ditemukan, dikembangkan dan dibuktikan melalui sebuah proses pengumpulan data yang sistematis dan analisis data tentang fenomena yang ada. Oleh karena itu kumpulan data, analisis dan teori akan saling mempengaruhi satu sama lain.

Penelitian GT memberikan peneliti suatu kemampuan untuk menurunkan atau menciptakan sebuah teori dalam konteks data yang telah dikumpulkan. Istilah Grounded Theory pertama kali diperkenalkan oleh Glaser dan Strauss pada tahun 1967. Dalam bukunya yang berjudul The Discovery of Grounded Theory Strategies for Qualitative Research. Strauss dan Corbin [19] menyimpulkan bahwa GT adalah sebuah teori yang diturunkan dari data yang secara sistematis dikumpulkan dan dianalisis dan data tersebut berasal dari proses pengamatan di lapangan. Perbedaan antara metode GT dengan metode lainnya adalah pada pendekatan filosofis, yaitu adanya hubungan kontinu antara pengumpulan data dan analisis data hubungan yang berkesinambungan antara proses pengumpulan data dan analisis data.

Desain framework maturity of $R L$ ini dikembangkan dari pendekatan GT. Banyaknya bukti-bukti implementasi RL walaupun sangat sederhana, memungkinkan sebuah teori baru dapat dimunculkan. Proses induksi merupakan langkah penting bagi seorang peneliti untuk menelaah data-data yang ada menjadi sebuah teori. Berdasarkan penelitian Heath dan Cowley [8], imaginasi dan kreatifitas peneliti sangat membantu untuk memunculkan sebuah teori baru. Sebuah data digunakan untuk menyelesaikan sebuah permasalahan. Hal ini membuat sebuah teori baru akan lebih masuk akal. GT juga akan mampu mengenali tidak hanya analytical generalization tetapi statistical generalization sehingga teori yang dibentuk akan sangat tepat terhadap permasalahan yang terjadi (Bernon et al. [17]). Randall dan Mello [20] melaporkan bahwa kemampuan dari GT adalah untuk mengatasi behavioral dimensions at the individual, organizational dan inter-organizational level. Manfaat lain yang dapat diambil dari GT ini adalah GT mampu mengevaluasi kekakuan dan kredibilitas suatu teori sehingga lebih fleksibel (Manuj dan Pohlen [21]). Agar penelitian lebih sistematis dan terstruktur, maka proses pengambilan data yang dilakukan dilapangan ataupun tidak harus memiliki suatu mekanisme tersendiri proses pengambilan data primer (pengamatan langsung di lapangan) atau data sekunder (data perusahaan dan studi literatur) harus memiliki mekanisme tersendiri. Hal ini bertujuan untuk menghindari bias yang terlalu besar antara data yang satu dengan yang lainnya. Antar data akan dapat mendukung data lainnya untuk memunculkan sebuah teori yang baru.

Gambar 1 menjelaskan langkah-langkah yang dilakukan dalam GT. Terdapat 4 langkah yaitu: (1) Fase pengumpulan data: Pada fase ini dilakukan tinjauan ulang literatur teknis Tinjauan ulang terhadap literatur yang memiliki persamaan content dan topik yang sama. Hal ini dimaksudkan untuk mengetahui sejauh mana kajian literatur atas phenomena yang terjadi. Langkah berikutnya ada- 
lah pemilihan kasus sebagai penelitian awal untuk membuktikan phenomena dengan bukti-bukti yang ada melalui data primer, sekunder dan melihat langsung ke lapangan. (2) Fase penyusunan data: Fase ini dilakukan 3 langkah yaitu open coding, axial coding dan selective coding. Tujuannya adalah pengelompokkan bukti-bukti yang ada dengan teori yang akan dibangun.pengelompokkan bukti-bukti yang terjadi di lapangan sehingga teori yang akan dibangun sesuai dengan tujuan yang diinginkan dan permasalahan yang terjadi. (3) Fase analisis data: Pada fase ini teori telah dibangun dari bukti-bukti yang terjadi di lapangan, karena GT merupakan metode induksi yaitu menciptakan sebuah teori baru yang didasarkan atas phenomena yang terjadi. Hal ini terjadi karena teori atau metode yang ada sekarang ini kurang mampu untuk menganalisisnya, tentunya dengan analisa serta pembahasan yang melibatkan orang-orang yang berkompeten di bidangnya. (4) Fase perbandingan literatur: Fase ini merupakan fase terakhir. Teori yang dibentuk tetap harus dilakukan kajian secara literatur dengan mempertimbangkan kelebihan serta kelemahan yang ada.

\section{Pengumpulan Data}

Dalam proses desain framework ini diperlukan kuesioner untuk menilai implementasi RL yang telah dilakukan oleh ketiga perusahaan elektronika konsumsi (sesuai dengan peta panduan (road map)Pengembangan Klaster Industri Prioritas Industri Elektronika dan Telematika, tahun 2010 - 2014 yang dikeluarkan oleh Departemen Perindustrian. Dalam buku tersebut terdapat klaster industri elektronika konsumsi yaitu semua produk elektronika yang banyak digunakan pada tingkat rumah tangga). Adapun perusahan elektronika konsumsi yang dijadikan obyek penelitian adalah PT. SA, PT. PCB dan PT. GMEI. Di samping itu, pengamatan secara langsung ke area perusahaan memberikan manfaat untuk menghindari perbedaan persepsi antara peneliti dengan perusahaan. Setelah kuesioner dikumpulkan maka dilakukan uji statistik yang meliputi uji kecukupan data, uji validitas dan uji reliabilitas. Setelah kesemua data valid dan reliable maka desain framework dimulai dengan metode Grounded Theory (GT). Uji statistik yang dilakukan adalah uji validitas dan relibilitas untuk melihat sejauh mana hasil kuesioner tidak bias dan responden mengerti atas pertanyaan dari kuesioner sehingga dapat mengurangi kesalahan pada waktu pengisian. Adapun langkah-langkah dalam GT antara lain: Fase pengumpulan data, fase penyusunan data, fase analisis data dan fase perbandingan literatur. Data yang dihasilkan dari penyebaran kuesioner tersebut merupakan data ordinal, untuk itu digunakan Method of Successive Interval (MSI) untuk mengubah ke data interval. MSI dibagi menjadi 7 tahapan yaitu: menghitung frekuensi $(\mathrm{F})$, menghitung proporsi $(\mathrm{P})$, menghitung proporsi kumulatif (PK), Mencari nilai Z, Menghitung densitas F (z), mengitung scale value (sc) dan menghitung nilai hasil penskalaan.

\section{Hasil dan Pembahasan}

Dari rangkaian tahapan yang telah dilakukan dalam metode GT, maka framework baru telah terbentuk berdasarkan atas fenomena yang terjadi dan perbandingan dengan literatur yang ada.

Berikut adalah tahapan dari metode GT untuk pengembangan framework.

Langkah pertama yang harus dilakukan adalah fase pengumpulan data. Data yang dikumpulkan disesuaikan dengan tujuan yang akan dicapai.

\section{Tinjauan Ulang Literatur Teknis}

Tinjauan ulang literature teknis dilakukan dengan tujuan agar penelitian yang dilakukan memiliki kontribusi kebaruan. Sehingga lileratur teknis dikumpulkan dan dianalisa untuk mempertegas bahwa penelitian yang dilakukan belum pernah diteliti orang lain. Di samping itu, tujuan lainnya adalah melihat sejauh mana perkembangan penelitian dengan ruang lingkup yang sama.

Pada tahun 1990 sampai dengan tahun 2008, penelitian RL berkisar pada ruang lingkup $R L$ input, $R L$ structure, $R L$ process dan $R L$ organization. Sekitar tahun 2008 sampai dengan 201, ruang lingkupnya sudah mulai berkembang. Adapun area cakupannya adalah masalah-masalah seperti customer satisfaction, secondary material, pricing, waste dan sustainability environment. Tahun 2011 sampai sekarang, masalah-masalah seperti framework, flexibility, corporate sosial responsibility (CSR), waste, policy (company, government, global), secondary material dan sustainability environment mulai terfokuskan.

\section{Pemilihan Kasus}

Kasus yang dipilih adalah kasus yang sering terjadi pada saat ini. Penelitian ini diharapkan dapat menyelesaikan permasalahan yang ada. Adapun kejadian yang ada adalah banyak perusahaan yang menganggap implementasi RL yang telah mereka lakukan nya sukses. Namun sampai saat ini belum ada metode atau framework yang dapat mengukur sampai sejauh mana tingkat kesuksesan yang telah dicapai. 


\section{Menyusun Protokol Pengumpulan Data}

Fase selanjutnya adalah menyusun protokol pengumpulan data. Penyusunan yang sistematis akan membantu peneliti untuk sistematika pengumpulan data yang diperlukan untuk penelitiannya. Datadata yang diambil berasal dari beberapa sumber seperti yang terlihat pada Tabel 1 yaitu berasal dari data primer, sekunder dan peneliti melihat langung ke lapangan untuk menangkap fenomena yang terjadi di lapangan. Adapun protokolnya dapat dilihat pada Tabel 1.

\section{Fase Penyusunan Data}

Fase pengumpulan data terdiri dari 2 coding yaitu open coding dan axial coding.

\section{Open Coding}

Open coding: proses merinci, menguji, membandingkan, konseptualisasi, dan melakukan kategorisasi data. Disamping itu terdapat pelabelan fenomena serta penamaan kategori tersebut sehingga proses pengelompokkan peristiwa dapat ter-cluster dengan jelas seperti yang terlihat pada Tabel 2 .

\section{Axial Coding}

Axial coding: mengidentifikasi suatu fenomena sentral, mengeksplorasi kondisi kausal, menspesifikasi strategi-strategi mengidentifikasi konteks dan kondisi yang mempengaruhi dan mendeskripsikan konsekuensi-konsekuensi untuk fenomena tersebut. Dalam Tabel 3 dijelaskan bahwa sebuah masalah akan dicari akar permasalahannya, solusi yang ditawarkan sampai dengan konsekwensi yang terjadi atas permasalahan tersebut.

\section{Fase Analisis Data}

Pada fase ini adalah sebuah fase yang menghasilkan sebuat teori baru. Teori yang dapat dibentuk adalah sebuah framework yang berfungsi sebagai alat pengukur tingkat keberhasilan implementasi RL. Disamping itu juga framework ini juga membantu perusahaan meningkatkan level maturity dari implementasi RL karena framework ini dilengkapi dengan 5 RL Aspek yang dibagi kedalam 21 indikator yang jelas.

\section{Fase Perbandingan Literatur}

Dalam tahap ini, framework sudah terbentuk, perbandingan dengan literature yang ada diperlukan untuk mengetahui kelebihan serta kekurangan dari desain framework yang sudah ada. Fase ini sangat penting sebagai bagian dari future research. Membandingkan framework yang telah dibuat dengan penelitian yang lain akan memungkinkan terjadi diskusi untuk kesempurnaan disain framework yang akan datang. Hal dimungkinkan karena keterbatasan informasi yang dimiliki oleh peneliti sebelumnya.

Setelah melewati metode GT maka desain Framework RL maturity level yang terbentuk (Gambar 2).

Gambar 2 menjelaskan bahwa framework ini terdiri dari 5 tingkatan yang terdiri dari Level 1: Conventional; Level 2: Managed; Level 3: Developed; Level 4: Innovative dan Level 5: Optimized. Untuk melihat sampai sejauh mana desain framework maturity ini mempunyai standarisasi yang jelas dan harus ada dalam setiap desain framework maturity, maka dilakukan komparasi terhadap beberapa penelitian sejenis. Antara lain penelitian yang telah dilakukan

Tabel 1. Protokol pengumpulan data

\begin{tabular}{|c|c|}
\hline \multirow{7}{*}{$\begin{array}{l}\text { Data } \\
\text { primer }\end{array}$} & Framework Maturity Level of RL \\
\hline & $\begin{array}{l}\text { Data didapatkan dari observasi ke lapangan, } \\
\text { deep interview dengan decision maker dan } \\
\text { peyusunan serta penyebaran kuesioner }\end{array}$ \\
\hline & $\begin{array}{l}\text { Penggunaan secondary material dalam proses } \\
\text { produksi }\end{array}$ \\
\hline & $\begin{array}{l}\text { Proses produksi (inventory system, factory } \\
\text { capacity) }\end{array}$ \\
\hline & $\begin{array}{l}\text { Alur RL secara keseluruhan (collecting } \\
\text { product, technology, waste treatment, claim, } \\
\text { Jumlah produk return) }\end{array}$ \\
\hline & Company Organization \\
\hline & Alur Servis, Alur klaim \\
\hline Data & Analisa tingkat implementasi RL \\
\hline sekunder & $\begin{array}{l}\text { Kompleksitas aktivitas dan aktor masing- } \\
\text { masing level }\end{array}$ \\
\hline $\begin{array}{l}\text { Masuk k } \\
\text { lapangan }\end{array}$ & $\begin{array}{l}\text { Pengamatan langsung terhadap obyek } \\
\text { penelitian ( } 3 \text { perusahaan, PT.PCB, PT.GMEI } \\
\text { dan PT.SA) }\end{array}$ \\
\hline
\end{tabular}

Tabel 2. Open coding

\begin{tabular}{ll}
\hline Coding & Keterangan \\
\hline A.1 & Kategori tingkat keberhasilan implementasi \\
& RL (level conventional, level managed, level \\
& developed, level innovative, level optimized) \\
A.2 & Kategori RL Aspect (Tingkat keberhasilan RL \\
& dapat dilihat dari beberapa aspek antara lain \\
& Information technology, production planning, \\
& distribution, business process dan environ- \\
& mental) \\
& Kategori indikator keberhasilan implement- \\
& tasi RL (Selain beberapa aspek yang di- \\
& jadikan bahan penilaian, perlu adanya indi- \\
& kator yang lebih detail sehingga penilaian \\
& implementasi RL lebih menyeluruh. Adapun \\
& indikator yang dipergunakan dalam pene- \\
& litian ini adalah 21 indikator yang terbagi \\
& dalam 5 aspek.) \\
\hline &
\end{tabular}


Tabel 3. Axial coding

\begin{tabular}{ll}
\hline Coding keterangan \\
\hline B.1 & $\begin{array}{l}\text { Causal condition: Kondisi yang menjadi penyebab. } \\
\text { (Banyak perusahaan yang sudah mengimplemen- } \\
\text { tasikan dan mendapatkan manfaat dari imple- } \\
\text { mentasi RL. } \\
\text { B.2 }\end{array}$ Central phenomenon: Fenomena sentral atau \\
& $\begin{array}{l}\text { utama yang menjadi fokus penelitian. Fenomena } \\
\text { sentral pada penelitian ini adalah tingkat }\end{array}$ \\
maturity dari implementasi RL. & $\begin{array}{l}\text { Consequences: Konsekuensi yang terjadi adalah } \\
\text { dengan adanya framework ini akan dapat }\end{array}$ \\
merubah pola berfikir & $\begin{array}{l}\text { Strategies: Strategi yang dilakukan. Pada fase ini } \\
\text { setiap perusahaan dengan melihat indikator dan } \\
\text { capaian yang jelas. } \\
\text { Context: Situasi yang mempengaruhi terjadinya } \\
\text { sebuah aksi. Banyak metode yang ada yang dapat } \\
\text { meminimasi biaya. } \\
\text { Intervening Condition: Faktor penghambat atau } \\
\text { faktor yang mempermudah terjadinya suatu } \\
\text { kejadian atau perilaku (aksi) }\end{array}$ \\
\hline
\end{tabular}

Tabel 4. Kelebihan dan kekurangan framework

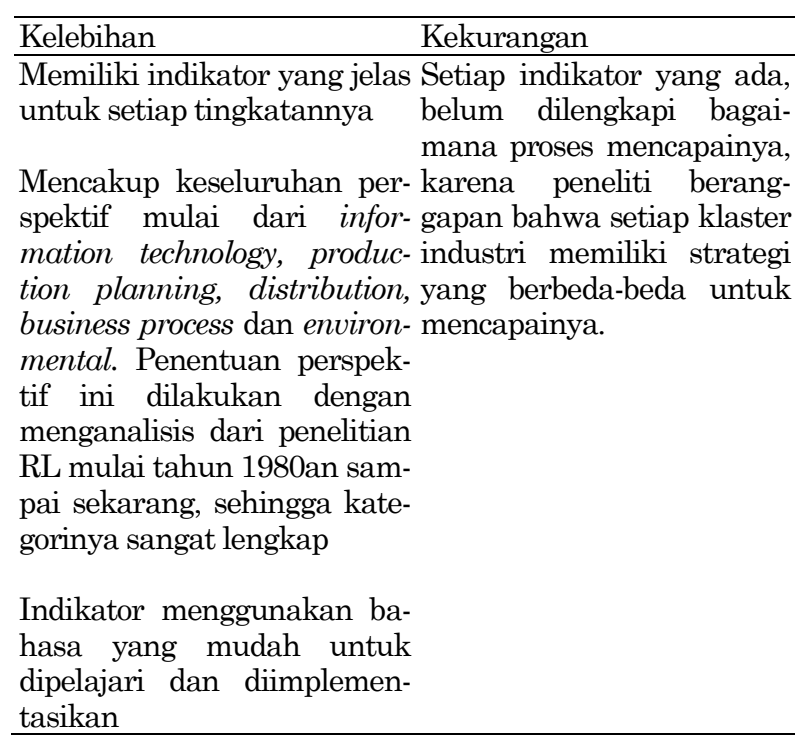

oleh Kwak dan Ibbs [22]; Constantinescu dan Iacob [23]; Grim [24]; Tan et al. [25]; Dadhich dan Chauhan [26]. Adapun beberapa kesamaannya antara lain sebagai berikut:

Kwak dan Ibbs [22]: Terdapat 5 tingkatan maturity levels yang terdiri dari initiating, planning, executing, controlling dan closing.

Setiap level terdapat assessment indicators yaitu integration, scope, time, cost, quality, communication, human resources, risk, dan procurement

Constantinescu dan Iacob [23]: Dikembangkan sebuah framework yaitu capability maturity model integration. Dalam frameworknya terdapat 6 capability levels yaitu: Level 0: Incomplete, Level 1: Performed, Level 2: Managed, Level 3: Defined,
Level 4: Quantitatively managed dan Level 5: Optimizing.

Di samping itu juga framework ini dibagi kedalam 22 process area yang terkelompok kedalam 4 area.

Grim [24]: Framework yang dikembangkan oleh Terry Grim ini diaplikasikan pada foresight services. Dalam framework yang dikembangkan level maturity dibagi kedalam 5 level yaitu: Lavel 1: $A d H o c$, aware, capable, mature dan world class.

Pada Level 2 dibagi ke dalam 3 assessment indicators, level 3 terdapat 3, Level 4 terdapat 4 dan Level 5 terdapat 3 assessment indicators.

Tan et al., [25]: Dalam framework yang dibuatnya yaitu The Enterprise Business Intelligence Maturity (EBIM). Model terdapat 5 level maturity yaitu: Level initial, repeatable, defined, managed dan optimizing.

Di samping itu terdapat 4 assessment indicators yang terdiri dari information quality, master data management, warehousing architecture, dan analytic.

Adapun persamaan dari beberapa penelitian maturity di atas adalah: (1) Setiap maturitynya memiliki tingkatan yang jelas Contoh: Level 1, Level 2 dan lain-lain. (2) Setiap level/tingkatan memiliki nama yang mewakili tingkatan tertentu Contoh: Level Conventional, Level Managed. (3) Informasi yang jelas untuk tiap-tiap tingkatan. (4) Setiap tingkatan memiliki KPI (Key Performance Indicators). Dapat diaplikasikan dalam proses kerja dan mempunyai fungsi penilaian.

\section{Studi Kasus}

Terdapat 3 perusahaan elektronika konsumsi yang dipakai sebagai obyek penelitian untuk mengukur serta menilai framework yang telah disusun oleh peneliti. Adapun perusahan-perusahaan tersebut adalah PT.PCB, PT. SA dan PT.GMEI. Perusahaanperusahaan tersebut bergerak dalam perusahaan elektronik konsumsi seperti pembuatan TV, AC, Lemari Es, Video, Mesin Cuci dan Lampu. Data yang dikumpulkan oleh peneliti berasal dari data primer berupa pengisian kuesioner oleh pihak manajemen perusahaan, interview secara langsung dan pengamatan langsung di lapangan. Sedangkan data sekunder didapatkan dari akses informasi lewat internet, rekapan data dari beberapa service center/ station dan data-data dari perusahaan itu sendiri. Berikut ini adalah gambaran umum alur RL untuk perusahaan elektronika konsumsi khususnya produk TV secara umum yang dilakukan oleh PT. PCB. 


\begin{tabular}{|c|c|}
\hline $\begin{array}{l}\text { LeVEl } 1 \\
\text { CONVENTIONAL }\end{array}$ & $\begin{array}{l}\text { - Traditional process, no implementation reverse logistics, no } \\
\text { benefit and understanding }\end{array}$ \\
\hline $\begin{array}{l}\text { Level } 2 \\
\text { MANAGED }\end{array}$ & $\begin{array}{l}\text { - Beginning to understanding reverse logistics benefit, but poorly } \\
\text { for its implementation, defining process, collaboration with third } \\
\text { parties services }\end{array}$ \\
\hline $\begin{array}{l}\text { LeVel } 3 \\
\text { DEVELOPED }\end{array}$ & $\begin{array}{l}\text { - Good controbs on service return, product quality, participate } \\
\text { environmental obligations, comprehension of reverse logistics } \\
\text { systems }\end{array}$ \\
\hline $\begin{array}{l}\text { LeVel } 4 \\
\text { INNOVATIVE }\end{array}$ & $\begin{array}{l}\text { - Finding more innovation in any sectors to minimize total reverse } \\
\text { logistics costs (design product, warranty claim product, learning } \& \\
\text { system thinking process, waste treatment) }\end{array}$ \\
\hline $\begin{array}{l}\text { Level } 5 \\
\text { OPTIMIZED }\end{array}$ & $\begin{array}{l}\text {-Focus to optimize continuous process improvement (pioneer \& } \\
\text { world class product, environmentally product, waste treatment, } \\
\text { good relationship along supply chain actors, managing customer } \\
\text { satisfaction \& loyalty }\end{array}$ \\
\hline
\end{tabular}

Gambar 2. Framework of reverse logistics maturity level Pulansari et al. [28]

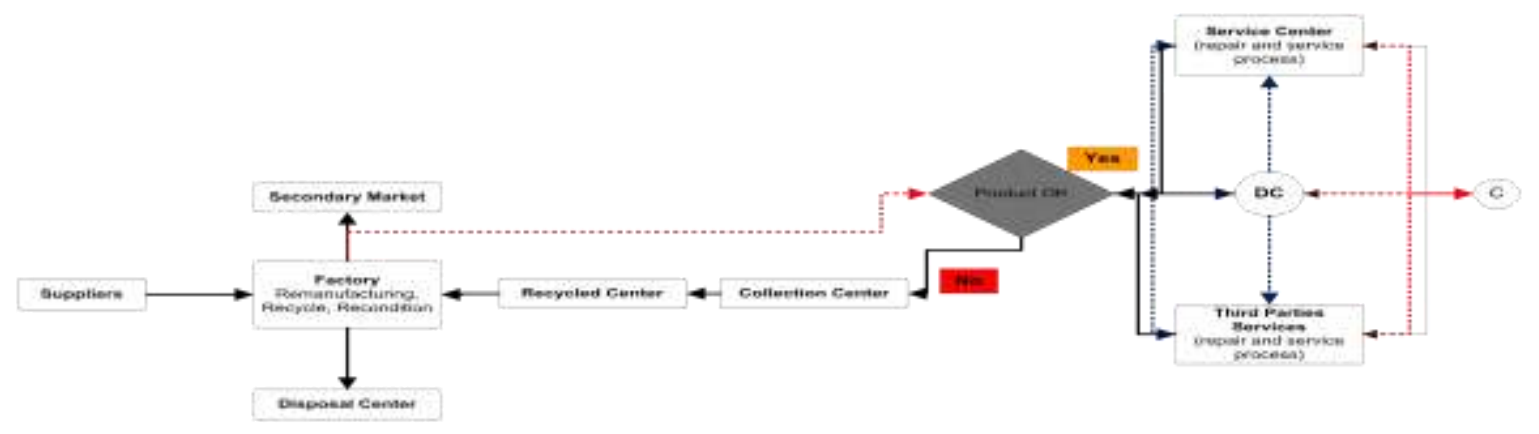

Gambar 3. Alur RL untuk produk elektronika secara umum

Gambar 3 menjelaskan tentang alur RL pada produk TV, Lampu dan Video yang dilakukan oleh tiga perusahaan elektronika konsumsi. Produk yang dikembalikan oleh konsumen dapat melalui tiga alternatif tempat yaitu kepada distribution center (DC) yang berupa toko, service center (SC) ataupun third parties services (TPS). Dari tempat-tempat tersebut apabila produk sudah tidak dapat lagi di repair maka akan dikumpulkan di collection center (CC). Selanjutnya produk tersebut akan dikirim ke recycled center (RC). Dari RC produk yang sudah mengalami disassembly sehingga bentuk fisiknya menjadi komponen-komponen, akan dikirimkan ke Factory untuk dilakukan proses selanjutnya.

Dari hasil uji validitas dan reliabilitas dapat disimpulkan bahwa data ini valid karena $\mathrm{r}$ hitung $>$ $r$ tabel. Dengan DF=N-2 dengan tingkat kepercayaan $95 \%$ atau probabilitas 0,05 maka didapatkan nilai $r$ tabel (tabel $r$ ) didapatkan hasil 0,4227 . Nilai corrected item-total correlation didapatkan bahwa nilainya lebih besar dari $\mathrm{r}$ tabel, oleh karena itu maka data PT.PCB, PT. SA dan PT. GMEI adalah valid. Untuk melihat apakah data ini dikatakan reliable maka nilai Cronbach's alpha harus $>0,6$ (Tavakol dan Dennick [27]. Nilai Cronbach's alpha based on standardized item nilainya sebesar 0,891 .

Tabel 6, 7 dan 8 menunjukkan hasil dari transformasi nilai ordinal ke nilai interval dengan menggunakan metode MSI untuk PT.PCB, PT.SA dan PT. GMEI. Adapun nilainya yang didapat antara lain berturut-turut: 2,049; 2,061 dan 2,061. Dalam Tabel 7 dan 8 didapatkan angka yang sama yaitu 2,061. Hal dikarenakan total nilai yang didapatkan oleh kedua perusahaan dalam pengisian kuesioner memiliki nilai yang sama. Dalam perhitungan MSI akan dihasilkan nilai yang sama. Akan tetapi apabila ditelaah lebih lanjut ada beberapa aspek yang nilainya berbeda. Aspek information technology dan business process memiliki nilai yang berbeda. PT S.A memiliki nilai information technology lebih tinggi dibandingkan PT. G.M.E.I sebaliknya PT. G.M.E.I memiliki nilai business process lebih tinggi dari PT S.A, walaupun nilai akhir MSI menunjukkan angka yang sama seperti Table 7 dan 8 . 
Tabel 5. Indikator implementasi $R L$

\begin{tabular}{|c|c|}
\hline RL Aspects & Assessment indicators \\
\hline Information & 1. Develop of RL concepts \\
\hline technology & $\begin{array}{l}\text { 2. Benefit from implementation } R L \\
\text { 3. Servicing to claim problem, warranty } \\
\text { product and product repair }\end{array}$ \\
\hline \multirow[t]{4}{*}{$\begin{array}{l}\text { Production } \\
\text { planning }\end{array}$} & $\begin{array}{l}\text { 1. Balancing between inventory system } \\
\text { and demand }\end{array}$ \\
\hline & 2. Leading to ICT / digital products \\
\hline & 3. Produce high quality product \\
\hline & 4. Timeliness of services \\
\hline \multirow[t]{3}{*}{ Distribution } & $\begin{array}{l}\text { 1. The synergistic relationship between } \\
\text { all actors } R L \text { systems }\end{array}$ \\
\hline & 2. Process of collecting product \\
\hline & 3. Collection center/station \\
\hline Business & 1. Leadership \\
\hline \multirow{6}{*}{ process } & 2. Strategic planning \\
\hline & 3. Customer \& market focus \\
\hline & $\begin{array}{l}\text { 4. Measurement, analysis \& knowledge } \\
\text { management }\end{array}$ \\
\hline & 5. Human resources focus \\
\hline & 6. Process management \\
\hline & 7. Business result \\
\hline \multirow[t]{4}{*}{ Environmental } & 1. Water waste treatment \\
\hline & 2. High technology to minimize waste \\
\hline & $\begin{array}{l}\text { 3. Participate to environmental } \\
\text { legislation }\end{array}$ \\
\hline & 4. Utilization secondary material \\
\hline
\end{tabular}

Tabel 6. Hasil transformasi data ordinal ke data interval PT.PCB

\begin{tabular}{cccccccc}
\hline $\begin{array}{c}\text { Ordinal } \\
\text { scoring } \\
\text { scale }\end{array}$ & Freq & Prop & $\begin{array}{c}\text { Cum. } \\
\text { prop. }\end{array}$ & Z scale & $\begin{array}{c}\text { Density } \\
\mathrm{F}(\mathrm{Z})\end{array}$ & $\begin{array}{c}\text { Scale } \\
\text { value } \\
\text { (S.V.) }\end{array}$ & $\begin{array}{c}\text { Value of } \\
\text { scaling }\end{array}$ \\
\hline 1 & 1 & 0,04545 & 0,04545 & $-1,69$ & 0,09568 & $-2,10498$ & 1 \\
2 & 4 & 0,18181 & 0,22727 & $-0,62272$ & 0,32871 & $-1,28166$ & 0,82331 \\
3 & 13 & 0,59090 & 0,81818 & 2,33397 & 0,02618 & 0,51196 & 2,61694 \\
4 & 3 & 0,13636 & 0,95454 & 1,69 & 0,09568 & $-0,50960$ & 1,59537 \\
5 & 1 & 0,04545 & 1 & 0 & 0 & 2,10498 & 4,20996 \\
$\Sigma$ & 22 & & & & & MEAN & 2,04912 \\
\hline
\end{tabular}

Tabel 7. Hasil transformasi data ordinal ke data interval PT.SA

\begin{tabular}{cccccccc}
\hline $\begin{array}{c}\text { Ordinal } \\
\text { scoring } \\
\text { scale }\end{array}$ & Freq & Prop & $\begin{array}{c}\text { Cum. } \\
\text { prop. }\end{array}$ & Z scale & $\begin{array}{c}\text { Density } \\
\text { F (Z) }\end{array}$ & $\begin{array}{c}\text { Scale } \\
\text { value } \\
\text { (S.V.) }\end{array}$ & $\begin{array}{c}\text { Value of } \\
\text { scaling }\end{array}$ \\
\hline 1 & 1 & 0,04545 & 0,04545 & $-1,69$ & 0,09568 & $-2,10498$ & 1 \\
2 & 4 & 0,22727 & 0,22727 & $-0,72559$ & 0,30668 & $-0,92842$ & 1,17655 \\
3 & 13 & 0,59090 & 0,86363 & 2,33397 & 0,02618 & 0,47468 & 2,57967 \\
4 & 3 & 0,09090 & 0,95454 & 1,69 & 0,09568 & $-0,76441$ & 1,34057 \\
5 & 1 & 0,04545 & 1 & 0 & 0 & 2,10498 & 4,20996 \\
$\Sigma$ & 22 & & & & & MEAN & 2,06135 \\
\hline
\end{tabular}

Tabel 8. Hasil transformasi data ordinal ke data interval PT. GMEI

\begin{tabular}{cccccccc}
\hline $\begin{array}{c}\text { Ordinal } \\
\text { scoring } \\
\text { scale }\end{array}$ & Freq & Prop & $\begin{array}{c}\text { Cum. } \\
\text { prop. }\end{array}$ & Z scale & $\begin{array}{c}\text { Density } \\
\text { F (Z) }\end{array}$ & $\begin{array}{c}\text { Scale } \\
\text { value } \\
\text { (S.V.) }\end{array}$ & $\begin{array}{c}\text { Value of } \\
\text { scaling }\end{array}$ \\
\hline 1 & 1 & 0,04545 & 0,04545 & $-1,69$ & 0,09568 & $-2,10498$ & 1 \\
2 & 4 & 0,22727 & 0,22727 & $-0,72559$ & 0,30668 & $-0,92842$ & 1,17655 \\
3 & 13 & 0,59090 & 0,86363 & 2,33397 & 0,02618 & 0,47468 & 2,57967 \\
4 & 3 & 0,09090 & 0,95454 & 1,69 & 0,09568 & $-0,76441$ & 1,34057 \\
5 & 1 & 0,04545 & 1 & 0 & 0 & 2,10498 & 4,20996 \\
$\Sigma$ & 22 & & & & & MEAN & 2,06135 \\
\hline
\end{tabular}

Dengan nilai interval dari framework yang telah ditentukan, maka parameter transformasinya adalah sebagai berikut:

Nilai antara $0 \quad->=1=$ Level Conventional

Nilai antara $>=1->=2=$ Level Managed

Nilai antara $>=2->=3=$ Level Developed

Nilai antara $>=3$ - >=4 = Level Innovative

Nilai antara $>=4->=5=$ Level Optimized

Tabel 5 adalah hasil dari brainstorming dengan beberapa pihak antara lain peneliti, perusahaan, pakar reverse logistics dan pemerintah. Dari hasil diskusi maka didapatkan hasil untuk assesstment process dibagi ke dalam 5 process area dan 21 assesstment indicators.

\section{Pembahasan Lima Aspek dalam Level Managed}

Dari hasil perhitungan MSI yang menunjukkan perusahaan masih pada level 2, maka berikut ini adalah karakteristik Level Managed yang dilihat dari kelima aspek meliputi information technology, production planning, distribution, business process dan environmental.

\section{Aspek Information Technology}

Paradigma berfikir perusahaan yang masih awam tentang konsep RL. Informasi tentang RL masih sangat sulit didapatkan, RL GDSS (Group Discussion Support System) masih jarang ada sehingga wacana, manfaat serta informasi terbaru RL sangat sulit didapatkan.

Antara manfaat yang akan dirasakan oleh perusahaan dengan biaya yang dikeluarkan sesuai konsep RL tidak akan sebanding.

\section{Aspek Production Planning}

Sistem manajemen inventory masih sangat sederhana sehingga memungkinkan ketidakseimbangan antara demand dan supply karena part sering mengalami keterlambatan. Perusahaan mulai mengarahkan produknya berbasis digital/ICT sehingga lebih ramah lingkungan dan hemat energy. Produk memiliki kualitas sedang.

\section{Aspek Distribution}

Perusahaan telah memiliki fasilitas distribusi yang sederhana yang melingkupi collection center, recycled center serta distributor dalam hal ini adalah retailer untuk memudahkan forward dan reverse berjalan dengan baik.

Dalam 1 kota hanya terdapat 1 service center resmi milik perusahaan. Ada kalanya dalam 1 kota juga 
belum ada tetapi perusahaan telah menjalin kerjasama dengan pihak ketiga.

\section{Aspek Business Process}

Perusahan telah memiliki visi dan misi untuk pegembangan perusahaan. Mulai pengembangan produk, penjualan produk, training karyawan. Tetapi kesemua konsep ini untuk mendorong terciptanya produk yang terbuat dari virgin material bukan pemanfaatan sencodary material dan waste yang dihasilkan dari proses produksi atau setelah produk habis masa pakainya.

\section{Aspek Environmental}

Sistem pengolahan limbah yang sifatnya masih sederhana. Manajemen waste telah diterapkan oleh perusahaan dalam setiap lini perusahaan. Perusahaan ikut serta mendukung dan mensukseskan peraturan perundang-undangan tentang lingkungan hidup.

Dari penentuan parameter transformasinya maka ketiga perusahaan menduduki Level 3 atau Developed. Adapun ciri-ciri perusahaan pada level ini dari ke lima aspek di atas adalah: (1) aspek information technology, perusahaan mengerti dan memahami konsep reverse logistics dan mengaplikasikannya secara sederhana. Perusahaan bekerja sama dengan pihak ke-3 dalam perbaikan produk dan menangani masalah klaim serta garansi produk dengan integrasi IT yang semakin baik. (2) aspek production planning sistem manajemen inventory pada perusahaan masih sangat sederhana sehingga memungkinkan ketidakseimbangan antara demand dan supply karena part sering mengalami keterlambatan. Terdapat manajemen inventori (ketersediaan part) dan waktu untuk servis sehingga tidak melampaui due date (3) aspek distribution, perusahaan sudah terbentuk sistem informasi manajemen (SIM) yang handal sehingga pelaku-pelaku reverse dapat memonitor perkembangan dan saling memberikan informasi-informasi terbaru Perusahaan memiliki $>2$ service center/station di tiap-tiap kota dan manajemen distribusi yang telah berjalan dengan baik. (4) aspek business process. Perusahaan tidak hanya memiliki customer service/station, tetapi perusahaan sudah memiliki strategi untuk meningkatkan kepuasan konsumen. Perusahaan sudah melakukan proses edukasi reverse logistics untuk tahap yang masih dasar atau sederhana. (5) aspek environmental. Perusahaan sudah memiliki sistem pengolahan limbah Tingkat 1/ Primary Treatment yaitu sistem pengolahan limbah yang memastikan zat-zat berbahaya yang digunakan pada proses produksi diolah sedemikian rupa sehingga aman bagi lingkungan. Ikut serta mengkampayekan kelestarian lingkungan dan mendukung program pemerintah.

Hasil untuk Level 3 ini sudah dikonfirmasi dengan Perusahaan serta pengamatan langsung pada service center serta wawancara dengan konsumen yang telah menggunakan produk dari ketiga perusahaan.

\section{Simpulan}

Dalam pengembangan framework untuk mengukur tingkat keberhasilan implementasi reverse logistics ini terdapat 5 level yaitu Level Conventional, Managed, Developed, Innovative dan Level Optimized. Agar supaya pengukuran implementasi RL ini dapat terukur secara sistematis maka framework dibagi kedalam lima RL aspect antara lain: Information technology, production planning, distribution, business process dan environmental. Penentuan RL aspect ini didasarkan atas klaim beberapa perusahaan yang telah sukses dan mendapatkan manfaat dari implementasi RL. Dikarenakan tidak adanya strandarisasi ataupun parameter yang jelas dalam proses klaim tersebut, maka framework ini dilengkapi dengan 21 assessment categories untuk memudahkan perhitungan setiap levelnya.

Selain itu dalam penelitian ini didisain model RL yang diterapkan pada tiga industri elektronika. Konsumsi ini khususnya perusahaan lokal menempati level ke 2 yaitu Level Managed. Pada tingkatan ini perusahaan masih dalam taraf belajar konsep RL secara menyeluruh yang meliputi manfaat, ketersediaan SDM, modal, perubahan konsep berfikir sampai perubahan teknologi dan penggunaan material. Pada dasarnya perusahaan pada level ini sudah mengaplikasikan secara tidak langsung konsep RL, tetapi dalam strategi perusahaan konsep RL belumlah dimengerti dengan baik, baik di tingkat top management sampai lower management. Di samping itu peran serta pemerintah sebagai regulator sangat diperlukan untuk mendorong perusahaan dan masyarakat untuk ikut mensukseskan implementasi RL. Adapun nilai yang didapat dengan menggunakan metode MSI adalah berturutturut dari PT.PCB, PT.SA dan PT.GMEI adalah 2,0491; 2,0613 dan 2,0613.

\section{Ucapan Terima Kasih}

Penulis mengucapkan banyak terima kasih kepada Direktorat Penelitian dan Pengabdian Masyarakat, Direktorat Jenderal Pendidikan Tinggi (DIKTI) atas diterimanya Program Hibah Penelitian Tahun Anggaran 2015 Batch I Nomor: 079/SP2H/PL/DIT. LITABMAS/II/2015 tanggal 14 November 2014, DIPA Revisi 01 tanggal 29 Pebruari 2015. Adapun 
Hibah Penelitian Hibah Bersaing yang diterima dengan judul "Disain Framework of Reverse Logistics Maturity Level Menuju Kondisi Environmental Friendly, Green Product, Eco Efficiency dan Government Control \& Policy pada Klaster Industri Elektronika Konsumsi”

\section{Daftar Pustaka}

1. Mutha, A. and Pokharel, S., Strategic Network Design for Reverse Logistics and Remanufacturing using New and Old Product Modules, Computers \& Industrial Engineering, 56, 2009, pp. 334-346.

2. Stock, J. R., Reverse Logistics in the Supply Chain, Transport \& Logistics Florida University of South Florida, 2003

3. Chouinard, M., D’Amoursa, S. dan Aït-Kadia, D., Integration of Reverse Logistics Activities within a Supply Chain Information Sistem, Computers in Industry, 56, 2004, pp. 105-124.

4. Moore, R., Reverse Logistics-the Least Used Differentiators, Reverse Logistics Magazine, Fall, 2006.

5. Pollock, W. K., Using Reverse Logistics to Enhance Customer Service and Competitive Performance, Reverse Logistics Magazine, Nov/Dec, 2007.

6. Kumar, S. and Putnam, V., Crandle to Crandle: Reverse Logistics Strategies and Opportunities across Three Industry Sectors, International Journal of Production Economics, 115, 2008, pp. 305-315.

7. Rakesh Verma, V. V., Reverse Logistics (An Important Dimention of Supply Chain Management). Available: http//www.cooolavenues.com/ mba-journal/operation/reverse-logisticsimportant-dimention-supply-chainmanagement Accessed 19 May 2011.

8. Wrap,. Case Study: Reverse Logistics for Plasterboard a Unique Operation to Manage the Delivery of Plasterboard and Backhaul the Off-cuts and Wastage, Oxon, 2010.

9. Rose, C. M., Ishii, K., and Masui, K., How Product Characteristics Determine End-Of-Life Strategies, Manufacturing Modeling Lab. Department of Mechanical Engineering Stanford University, Stanford CA 94305-94321, 2002.

10. Wu, Y.-C. J., and Cheng, W.-P., Reverse Logistics in the Publising Industry: China, Hongkong and Taiwan, International Journal of Physical Distribution \& Logistics Management, 36, 2006, pp. 507-523.

11.Ho, G. T. S., Choy, K. L., Lam, C. H. Y., and Wong, D. W. C., Factors Influencing Implementation of Reverse Logistics: A Survey among Hong Kong Businesses, Measuring Business Excellence, 16, 2012, pp. 29-46.
12. Lau, K. H., and Wang, Y., Reverse Logistics in the Electronic Industry of China: A Case Study, Supply Chain Management: An International Journal, 14, 2009, pp. 447-465.

13. Rogers, D. S., and Tibben, R. S. L., Going Backwards: Reverse Logistics Trends and Practices, University of Nevada, Reno Center for Logistics Management., 1998.

14. deBrito, M., P, F., Simme, D. P., and Dekker, R., Reverse Logistics: A Review of Case Study, Econometrics Institute Report EI, 2004.

15. Heath, H., and Cowley, S., Developing a Grounded Theory Approach: A Comparison of Glaser and Strauss, International Journal of Nursing Studies 41, 2004, pp. 141-150.

16. Walker, D., and Myrick, F., Grounded Theory: An Exploration of Process and Procedure, Qualitative Health Research, 16, 2006, pp. 547-559.

17. Bernon, M., Rossi, S., and Cullen, J., Retail Reverse Logistics: A Call and Grounding Framework for Research, International Journal of Physical Distribution \& Logistics Management, 41, pp. 484-510.

18. Denk, N., Kaufmann, L., and Carter, C. R, Increasing the Rigor of Grounded Theory Research: A Review of the SCM Literature, International Journal of Physical Distribution \& Logistics Management, 42, 2012, pp. 742-763.

19. Glaser, B.G., and Strauss, A. L., The Discovery of Grounded Theory, Aldine Publishing Co., New York NY, 1967.

20. Randall, W. S., and Mello, J. E., Grounded Theory: An Inductive Method for Supply Chain Research. International Journal of Physical Distribution \& Logistics Management, 42, 2012, pp. 863-880.

21. Manuj, I., and Pohlen, T. L., A Reviewer's Guide to The Grounded Theory Methodology in Logistics and Supply Chain Management Research. International Journal of Physical Distribution \& Logistics Management, 42, 2012, pp. 784-803.

22. Kwak, Y. H. and Ibbs, C. W., Project Management Process Maturity (PM)2 Model, Journal of Management in Engineering, 18(3), 2002, pp. 150-155.

23. Constantinescu, R., and Iacob, I. M., Capability Maturity Model Integration, Journal of Applied Quantitative Methods, 2, 2007, pp. 31-37.

24. Grim, T., Foresight Maturity Model (FMM) Achieving Best Practices in the Foresight Field, Journal of Futures Studies, 13, 2009, pp. 69-80.

25. Tan, C. S., Sim, Y. W., and Yeoh, W., A Maturity Model of Entreprise Business Intelligence, IBIMA Publising, 2011.

26. Dadhich, R. and Chauhan, U., Integrating CMMI Maturity Level-3 in Traditional Software Design 
Process, International Journal of Software Engineering \& Applications, 3, 2012, pp.17-26.

27. Tavakol, M., and Dennick, R, Making Sense of Cronbach's Alpha, International Journal of Medical Education, 2, 2011, pp. 53-55.
28. Pulansari, F., Donoriyanto, D. S., Iriani, Proposed Maturity Framework for Reverse Logistics Implementation, Proceedings of the $3^{\text {rd }}$ Industrial Engineering and Service Science (IESS), Yogjakarta, Indonesia, 2015, pp.42-50. 